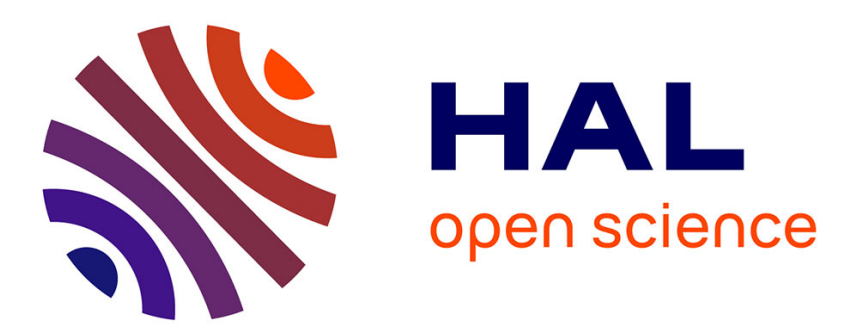

\title{
Titanium Superplastic Forming by Aurock: A Complete Integrated Solution from CAD File to Final Part
}

Olivier Barrau, Fabien Nazaret, Marion Le Fournier, Etienne Lebard, Yannick Le Maoult

\section{- To cite this version:}

Olivier Barrau, Fabien Nazaret, Marion Le Fournier, Etienne Lebard, Yannick Le Maoult. Titanium Superplastic Forming by Aurock: A Complete Integrated Solution from CAD File to Final Part. ICSAM 2015 - 12th International Conference on Superplasticity in Advanced Materials, Sep 2015, Tokyo, Japan. p. 488 - 493, 10.4028/www.scientific.net/MSF.838-839.488 . hal-01633699

\section{HAL Id: hal-01633699 \\ https://hal.science/hal-01633699}

Submitted on 25 Apr 2019

HAL is a multi-disciplinary open access archive for the deposit and dissemination of scientific research documents, whether they are published or not. The documents may come from teaching and research institutions in France or abroad, or from public or private research centers.
L'archive ouverte pluridisciplinaire HAL, est destinée au dépôt et à la diffusion de documents scientifiques de niveau recherche, publiés ou non, émanant des établissements d'enseignement et de recherche français ou étrangers, des laboratoires publics ou privés. 


\title{
Titanium Superplastic forming by Aurock: a complete integrated solution from CAD file to final part.
}

\author{
BARRAU Olivier ${ }^{1 a^{*}}$, NAZARET Fabien ${ }^{1 \mathrm{~b}}$, LE FOURNIER Marion $^{1 \mathrm{c}}$, \\ LEBARD Etienne ${ }^{2 \mathrm{~d}}$ and LEMAOULT Yannick ${ }^{2 \mathrm{e}}$ \\ ${ }^{1}$ Aurock, 54 rue Gustave Eiffel, 81000 Albi, France \\ ${ }^{2}$ Institut Clément Ader - Mines d'Albi, Campus Jarlard, FR-81013 Albi Cedex 09 \\ abarrau@aurock.fr, ’nazaret@aurock.fr; '9efournier@aurock.fr

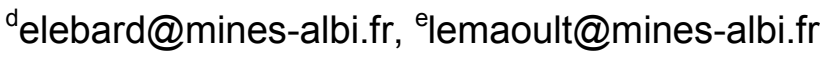

Keywords: SPF, Titanium, Aeronautical part, Simulation, numerical PID

\begin{abstract}
With its experience in the SPF (Super Plastic Forming) simulation and tool manufacturing, Aurock completes its offer in the titanium SPF field with the part forming and brings a global support from the conception up to the manufacturing. Aurock proposes tool design, forming strategy and simulation, rapid tool manufacturing made of refractory castable reinforced with metallic fibre and now titanium superplastic forming. To improve its offer, Aurock started from a blank page and developed a specific SPF press to test and assess new heating solutions. One major innovation permits to reduce the heating time using a direct sheet heating. The process becomes anisothermal. This approach avoid time to heat up to $900^{\circ} \mathrm{C}$ large toolings.

The completed offer for titanium SPF parts and successful results on the heating solutions are presented.
\end{abstract}

\section{Introduction}

Titanium is one of the most used metal for the Aeronautic industry around jet engine and airframe structure [1] due to its lightweight property combined with good mechanical properties from room temperature up to $600^{\circ} \mathrm{C}$. The titanium alloys combined with the SPF process offer large possibilities for complex part and can reduce assembly to a single part. The superplastic deformations are possible in a narrow gap of temperature $\left(870^{\circ} \mathrm{C}\right.$ to $950^{\circ} \mathrm{C}$ for TA6V for fine grain and can be reduced to $750^{\circ} \mathrm{C}$ for Ultra Fine Grain alloys). Then, it is necessary to keep a homogeneous and precise temperature of the sheet during all the forming phases. The deformation rate needs to be controlled too and maintained near $10^{-4} \mathrm{~s}^{-1}$.

The main drawbacks of the SPF are its high production costs and its low production rate due to a constant deformation rate during the forming and the high temperature needed to get the super plasticity. The strain rate has to be constant during the forming and it is difficult to reduce the cycling time without changing the microstructure of formed alloys. Furthermore, the total heating time are much greater than the forming cycle time. The first heating time is needed to get the tools and press platen up to $900^{\circ} \mathrm{C}$ which can last $48 \mathrm{~h}$ depending on the mass of the tools. The second heating time is used to re-heat the tool after unmolding the part and can last 1 or 2 hours (equivalent to one pressure cycle to form a part).

Aurock focuses its research on the high temperature drawback, because the forming cycle depends on a constant strain rate which is necessary to get superplasticity of the alloys. In the frame of a research project, Aurock designs and manufactures a superplastic press to form titanium alloys. This press allows several experimentations and innovations. These experiments are also done on a laboratory device dedicated to infra-red heating (IR abbreviation used hereafter as Infra-Red). 


\section{Why Infra-Red heating}

Several technics have been explored in order to reduce the heating time of SPF process. Induction [2] and infra-red heating [3] technologies were tested to heating directly the sheet. One difficulty with direct heating is to manage the thermal exchange between a hot sheet and a "cold" tool. The homogeneity of the sheet temperature is needed to ensure a good forming. But heating with IR leads to an anisothermal process and the regulation of sheet temperature during forming is the hard point to solve. Temperature control can be done with optical fiber with thermal insulator [3] or by using an IR camera to map the temperature [4]. In industrial conditions, such sensors are difficult to use due to the extreme conditions of temperature and pressure during forming. To avoid the use of these sensors, Aurock chooses to manage the temperature of the sheet with a numerical PID (PID means Proportional Integral Derivative -patented [5]) which takes into account the displacement of the sheet during forming and all the thermo-optical exchanges in the furnace.

If the heating with IR lamps can be used for industrial forming, the gains are numerous:

- The SPF press with IR lamp design is much simpler than conventional SPF press : it could be a cold press with small adjustments.

- Tool used at lower temperature (less than $500^{\circ} \mathrm{C}$ ) so less maintenance costs and better parts quality

- Higher process production rate : very quick sheet heating and quick tool change can be attained because it is almost cold.

- Energy savings can be achieved, because the furnace and tool need not be heated up to $900^{\circ} \mathrm{C}$ and the sheet can be heated up very quickly

- The tool releases a cold sheet that drastically reduces twisting

\section{Experimentation}

Superplastic forming tests. For the experimental forming, the ICA (Institut Clément Ader) has developed a laboratory device for superplastic forming where the sheet is heated by IR lamps. The lab press is composed with 8 lamps of $3000 \mathrm{~W}$, has a maximum hydraulic pressure of 25 tons and the maximum forming pressure can reach 40 bars. The lamps are unidirectional and each lamp measures the length of the furnace. The inner faces of the furnace are equipped with silica rigid panels to ensure insulation of the cover. The titanium alloy used for experiments is TA6V and the sheet size is $500 \times 500 \times 1.4 \mathrm{~mm}^{3}$. The tool and the sheet are both at room temperature at the beginning of the forming.

The die used is made of refractory castable reinforced with metallic fibres. This experimental tool has a simple design and has housings for several sensors. Thermocouples measure the die temperature during the forming. Some thermocouples are directly welded on the sheet in order to follow the temperature during the forming. The die bottom is open so that a bi-chromatic pyrometer can measure the sheet temperature during the forming. The pyrometer used is bi-chromatic to avoid the emissivity variation during oxidation of the sheet when it is heated up.

This experimental device allows to program the pressure cycle and the lamps intensities before forming, but also to change these parameters during the experiments. Sensors placed in the cover give a feedback of pressure and temperature in the cover cavity.

Finite Element Simulation of the SPF. Because the numerical simulation and PID will drive the process, the forming efficiency depends on the accuracy of the modelling of the process. The modelling has to be as close as possible to reality to get the best lamp intensities cycle which is the hard point to solve. This modelling involves thermo-mechanical and thermo-optical phenomena, so several characterizations are needed to get an accurate numerical model. Mechanical testing for a range of temperature are performed on TA6V with different strain rates commonly used in SPF that 
leads to a Norton-Hoff viscoplastic law. The thermo-optical behavior is assessed from room temperature up to $900^{\circ} \mathrm{C}$ for all involved components: TA6V sheet, IR lamps and the cover equipped with silica panels. The last data needed are the thermal resistance between the sheet and the die. All these characterizations allows to build a numerical model to predict the IR lamp intensities cycle.

All the relevant phenomena are modelled, such as thermal resistance between the tool and the die. The boundary conditions involve not only the sheet and the die but also the forming process itself. The software used are Abaqus $($ for the simulation and FORTRAN to implement the PID controller (Proportional, Integral and Derivate). For each numerical increment, the FORTRAN subroutine gives a power of lamps depending on the calculated temperature during the forming.

For each increment, the gap between set and measured temperature is calculated. The PID modifies the flux to reduce that gap. The power of the lamp cycle is deduced from the flux. If any solution cannot be found, the cover design will be revised: the change of the number and the position of the lamps, the maximal power delivered and the type of reflectors.

\section{Results}

Finite Element Simulation of the SPF. A cross section of the simulated system is given in Fig. 1. At first, a constant flux is applied to get a reference case (Fig. 2). From this case and by the way of a transfer function of the process with Scilab, a first set of PID parameters is obtained and implemented in Abaqus $\mathbb{C}$. Then, all the thermo dependent parameters (such as emissivity, density, specific heat,...) are implemented into the numerical model.

Each relevant phenomenon is modelled: the friction coefficient between the sheet and the tool, the thermal exchange (radiative and convective) between the sheet, the tool and the internal atmosphere of the press-furnace, and the thermal exchange of the cover with the outside at room temperature. For the simulation, a symmetry plane is considered.

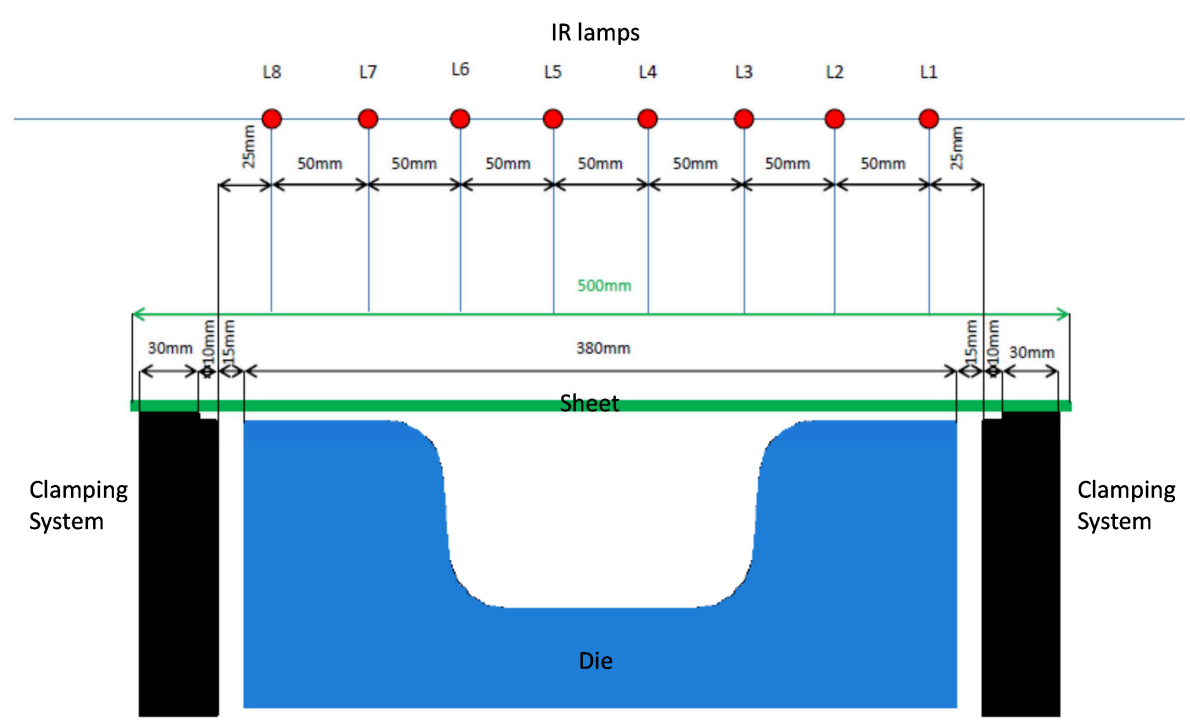

Fig. 1: Sketch of the simulated system: the die, the clamping system, the sheet and the 8 lamps.

At the beginning of the simulation, all the components are at room temperature. Then the sheet is heated up to the forming temperature, then the optimized pressure cycle is applied. The intensity is controlled for each lamp and the temperature is assessed for each nodes facing the lamps. This simulation will give the lamp intensity cycle to ensure a constant temperature in the sheet during the forming. The target temperature is $870^{\circ} \mathrm{C}$ during all the forming.

Due to the design of lamps equipped to the press, the flux have to be maintain between 25 and 70 $\mathrm{mW} / \mathrm{mm}^{2}$. The Fig. 2 presents the intensity of the lamps depending on time. From the beginning up to 1500 seconds, it is the time needed to heat and stabilize the temperature in the sheet. Beyond 
$1500 \mathrm{~s}$, the forming cycle is applied (pressure) and the intensity of the lamps changes depending on their position and elapsed time.

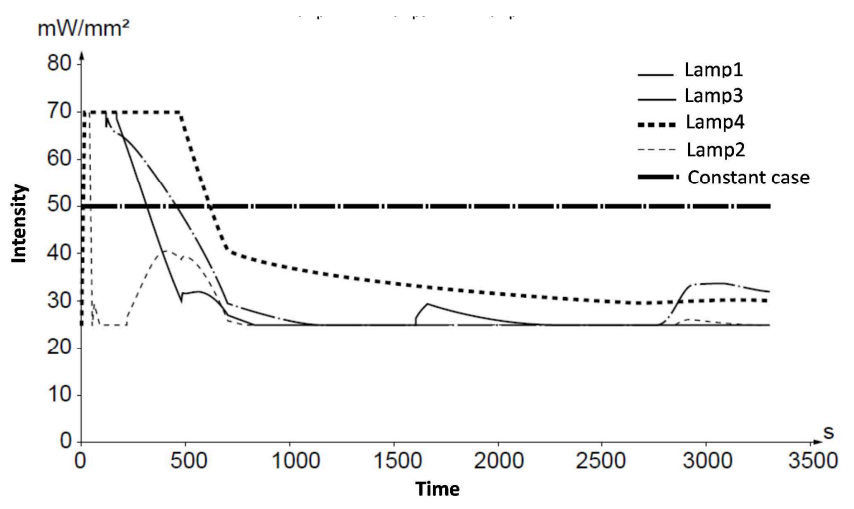

Fig. 2: Intensity of the 4 IR-lamps during the heating and the forming phases calculated by the PID controller implemented in a finite element simulation of the process.

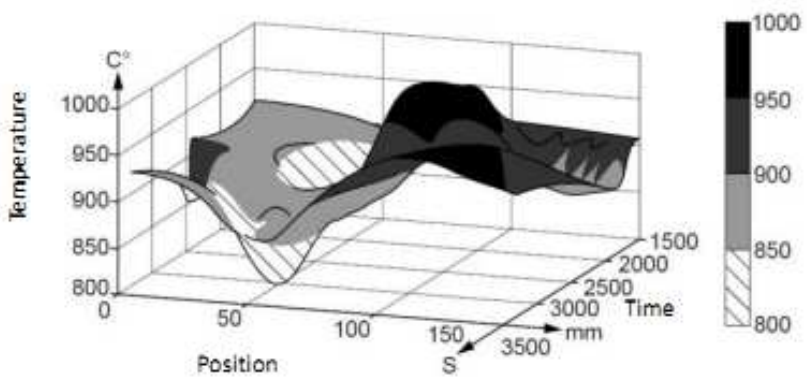

a - without PID

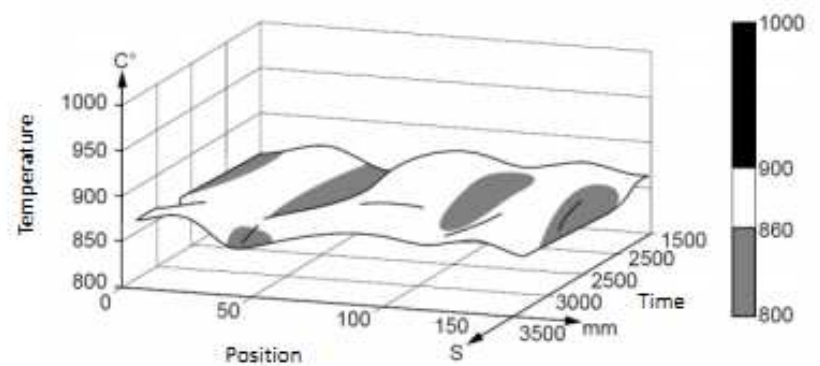

b - with PID

Fig. 3: Map of the calculated temperatures in a sheet section during the forming with a constant power of the lamps (a- without PID controller / b- with PID controller). 0mm position is the plan of symmetry of the sheet.

The temperature map during the forming without the PID controller is shown on Fig. 3 for a 2D section as shown in Fig. 1. The plane of symmetry corresponds to the $0 \mathrm{~mm}$ position on the graph. In this case, the mean temperature calculated for all the points and for all the increments is $901^{\circ} \mathrm{C}$ with a standard deviation of $35^{\circ} \mathrm{C}$. Fig. 3-b highlights the effect of the PID controller on these results: the mean temperature is now $862^{\circ} \mathrm{C}$ (target at $870^{\circ} \mathrm{C}$ ) and the standard deviation is $17^{\circ} \mathrm{C}$. As expected, the PID controller is needed to manage a homogenous temperature in the sheet during the forming.

Superplastic forming tests. The first experimental forming performed on the ICA press with a constant lamp intensity shows that it is not possible to form a part without overheating. In our case, the overheating leads to cracks that appears at the top radius due to the change of geometry. It is obvious that the intensity lamp cycle has to take into account the displacement of the sheet and also the tool geometry. The temperature measurement in situ during the process is possible but presents major drawbacks. Even with bi-chromatic pyrometer, the displacement of the sheet is a problem because the pyrometer work efficiently with a constant focal distance. Measurements perform with an optical fiber with thermal insulation [3] are not always effective due to the emissivity variations and sheet displacement. IR camera could also be a solution [4], but it need to add window on the cover and this window will affect the thermal behavior of the cover and may interfere with the lamp 
distribution. Furthermore, the sealing function of the cover becomes more complex with windows. In order to use this process in industrial conditions, it is not acceptable to have windows in the cover and a bottom opened tool. One way to work around this problem is the process simulation combined with the PID controller. It seems to be too complex to manage the lamp intensity during the forming and only numerical calculation can get a solution.

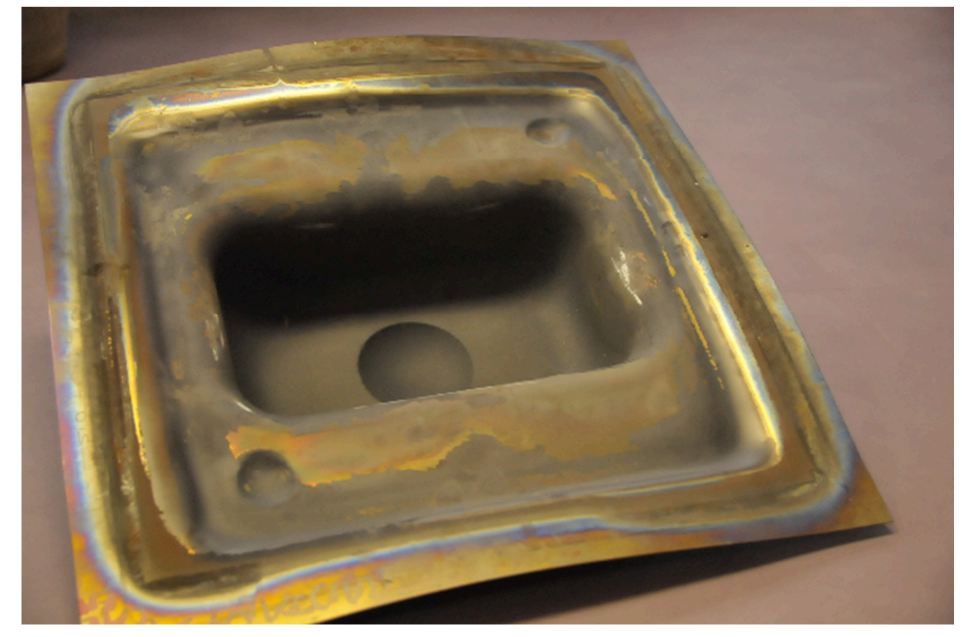

Fig. 4: Sheet formed by using optimized power of the lamps calculated with the PID controller implemented in a finite element simulation of the process. The border of the sheet shows the thermal gradient between the cold outer and the hot inner.

The PID controller and the process simulation give the lamp intensity cycle and the pressure cycle that are programmed into the press. The result of these cycles is shown in Fig. 4 . The part is totally formed and the hole in the bottom of the tool appears. These experiments performed with a dedicated tool allow to compare predicted and experimental temperatures of the components during the forming. The sensors used to measure the sheet temperature during the forming are not driving the process and are only used to compare to simulation forecast.

To be sure that the forming happens as expected, the thickness and the microstructure of the sheet have to be controlled. The thickness after forming was measured with a nondestructive ultrasonic sensor. The comparison between experimental and calculated measurements are in agreement. The main gap is located at the bottom of the vertical face and the fillet radius, but the difference never exceeds $0.2 \mathrm{~mm}$ (initial thickness at $1.4 \mathrm{~mm}$ ). SEM pictures have been taken of the microstructure of TA6V before and after the forming with IR heating. The two images are quite close and the initial $\alpha+\beta$ phases are present.

After these promising results, an energy study was done to compare the consumption of the Faste press with the conventional heating platen technology and the same press equipped with IR heater. This comparison is focused on the electrical consumption and the time needed to perform a batch of 20 parts of $1500 \times 1000 \mathrm{~mm}^{2}$. The total energy consumption for the conventional press is about 2430 KW.h and last 54 h. For the IR heater, the consumption fall to 1575 KW.h and last only 20.5 hours. The significant results are observed during the heating from room temperature up to $900^{\circ} \mathrm{C}$. With the IR lamp, only the sheet has to be heated and it could be done in only half an hour compare to one day for the heating platen technology (first heating of the tool and cover). This leads to an electrical consumption divided by 1.5 and mainly an occupation time divided by 2.6 if we consider a batch of 20 sheets. IR heaters only consume more power for the forming cycle (pressure cycle) compared to conventional heating. 


\section{Conclusion and perspectives}

This laboratory trials with Infra-Red heaters give promising results. Constant temperature is needed in the sheet during the forming, and hence this is the hardest point to solve during the sheet displacement. It seems easier to manage thermal exchange between the tool and the sheet. Concerning direct temperature measurement, it is very difficult to have a measure during the forming. In the same way, the intensity lamp cycle can only be defined by a numerical solution. This fully numerical approach coupling process simulation and numerical PID is very innovative and leads to a patent [5]. The first experimental results obtained with the numerical cycles of pressure and lamps intensity are promising. The gains expected with the IR heating are numerous and mainly concerns the energy savings and the machine-time.

The next steps on this on-going work will be done to get an accurate reliability of the numerical model and to test its robustness. Then an IR cover will be design to be used on an industrial press with a sheet of $1500 \times 1000 \mathrm{~mm}^{2}$. This forming test will be carried out with a more complex tool representative of the complex parts usually formed by SPF. Aurock hopes to offer in the next years a new way to perform the superplasticity with an anisothermal process.

\section{Acknowledgment}

The authors acknowledge the financial support awarded by the "Direction Générale de l'Armement (DGA)" through the RAPID financial support.

\section{References}

[1] G. Lutjering and J.C. Williams, Titanium, (2nd Edition, Springer, 2007)

[2] Paul S. Gregg, Marc R. Matsen, Superplastic forming using induction heating, The Boeing Company, USA, 1995, US5710132

[3] Theodore E. Leistner, Micahel J. Acker, Apparatus for shaping a metal workpiece, Mcdonnell Douglas Corporation, USA, 1982, US4474044

[4] Peter Spence, Richard Milburn, Method and apparatus for superplastically forming a workpiece, Spence Peter J., Milburn Richard G., USA, 2003, US20030000275

[5] Fabien Nazaret, Etienne Lebard, Yannick Le Maoult, Luc Penazzi, Vanessa Vidal, Vincent Velay, Procédé de pilotage d'une machine de formage superplastique et machine correspondante, Aurock-Armines, 2015, 15/53052

[6] Gérard Bernhart, Jean Paul Arcens, Yannick Le Maoult, "Innovative Superplastic Forming Based in In-Situ Infra-Red Sheet Heating”, Materials Science Forum 735 (2013) 415-421.

[7] Gilles Marin, Fabien Nazaret, Olivier Barrau, Nicolas Guegan, Benoît Marguet, Alain Dupuy, "Development of Double-Action SPF Forming Process by Finite Element Simulation for A380 Part”, Materials Science Forum 735 (2013) 162-169. 